\title{
Payer Preferences and Willingness to Pay for Genomic Precision Medicine: A Discrete Choice Experiment
}

\author{
Devender S. Dhanda, PhD, MS, MBA; David L. Veenstra, PharmD, PhD; \\ Dean A. Regier, PhD; Anirban Basu, PhD; and Josh J. Carlson, MPH, PhD
}

\begin{abstract}
BACKGROUND: Although precision medicine using genetic information offers significant promise, its uptake and eventual clinical and economic impacts are uncertain. Health care payers will play an important role in evaluating evidence and costs to develop coverage and reimbursement policies.

OBJECTIVE: To elicit U.S. health care payer preference for genomic precision medicine to better understand trade-offs among clinical benefits, uncertainty, and cost.

METHODS: Using key informant interviewer discussions ( $\mathrm{N}=6$ payers), we identified 6 key attributes of genetic tests important to payers: type of information the test provides (screening vs. treatment prediction), probability that the member has an informative genetic marker, expert agreement on changing medical care based on the marker, quality-of-life gains, life expectancy gains (with statistical uncertainty), and cost to the plan. We designed a stated preference discrete choice experiment using these attributes and administered a web survey to a sample of U.S. health care payers. We used effects coding and analyzed the data using an error component mixed logit modeling approach.
\end{abstract}

RESULTS: The survey response rate was $58 \%$ (150 participants completed the survey). Approximately $53 \%$ of respondents had previous experience evaluating genetic tests for reimbursement, and $85 \%$ had more than 5 years of health care decision-making experience. Payers valued improvements in quality of life the most (marginal willingness to pay [mWTP] of $\$ 1,513-\$ 6,076)$, followed by medical expert agreement on the treatment change (mWTP of $\$ 2,881-\$ 3,489$ ). Payers placed a relatively lower value for genetic tests with lower marker probability (mWTP of $\$ 2,776$ for highest marker probability to $\$ 423$ for lowest marker probability). Payers mWTP was lowest for resolving uncertainty in quality of life (mWTP of $\$ 1,513$ $\$ 2,031)$ and life expectancy gains $(\$ 536-\$ 1,537)$.

CONCLUSIONS: Payers exhibited a strong preference for genetic tests that improved quality of life, had high expert agreement on changing medical care, and increased life expectancy. These findings suggest that payers will need evidence of clinical utility to support coverage and reimbursement of genomic precision medicine.

J Manag Care Spec Pharm. 2020;26(4):529-37

Copyright $\odot 2020$, Academy of Managed Care Pharmacy. All rights reserved.

\section{What is already known about this subject}

The evolution of multigene sequencing has provided significant momentum for precision medicine.

Lack of consistency in coverage and reimbursement policies and lack of consistent evidentiary standards are among the several key barriers identified for implementation of genetic precision medicine.

\section{What this study adds}

Using a discrete choice experiment, we identified 6 attributes that were important to the U.S. payers for the evaluation of the genetic tests and demonstrated how payer preference varied according to the test's attributes.

Payers exhibited a strong preference for genetic tests that improved quality of life, had high expert agreement on changing medical care, and increased life expectancy.

These preferences are consistent with payer demands for evidence of clinical utility and clinical consensus of genetic test utilization.
$\mathrm{P}$ recision medicine-herein defined as the use of genetic information to guide clinical actions-can be used to implement preventative interventions based on disease risk or to tailor treatment regimens based on likely response or toxicity. ${ }^{1}$ The evolution of genetic testing from single-gene variant testing to multigene sequencing or even whole genomes has provided significant momentum for precision medicine because of its speed, accuracy, and low cost. However, coverage and reimbursement policies for precision medicine have been cited as a barrier to implementation. ${ }^{2}$

A recent study identified 5 key barriers for implementation of genetic testing, including 2 which focused on payers: the lack of consistency in coverage and reimbursement policies and lack of consistent evidentiary standards of clinical utility. ${ }^{3}$ In another study, Lu et al. (2018) found inconsistent coverage and reimbursement policies for clinical guideline-recommended pharmacogenomic tests (single-gene and multigene tests) for cancer. ${ }^{4}$ The variation in coverage and reimbursement policies was more prevalent for multigene tests compared with that of single-gene tests in oncology. Payers who covered multigene testing based their coverage policy on the clinical guideline recommendations and used evidence from a wide range of publications such as clinical validation studies, cohort studies, editorials, and reviews. ${ }^{5}$

To inform appropriate decision making about complex health technology innovations like genetic testing, health care stakeholders must weigh a variety of factors including benefits, harms, costs, and uncertainties. ${ }^{4,6}$ Stated preference discrete choice experiments (DCEs) have been successfully used to 


\section{TABLE 1 Attributes of Genetic Tests and Description of Corresponding Levels for Each Attribute}

\begin{tabular}{|c|c|}
\hline Test Attributes & Attribute Levels \\
\hline Information from a genetic test & $\begin{array}{l}\text { - Disease screening } \\
\text { - Treatment change } \\
\text { - Disease screening+treatment change }\end{array}$ \\
\hline Probability that your member has the genetic marker & $\begin{array}{l}\text { - } 1 \text { of } 100 \text { people tested will have the marker } \\
\text { - } 10 \text { of } 100 \text { people tested will have the marker } \\
\text { - } 30 \text { of } 100 \text { people tested will have the marker } \\
\text { - } 60 \text { of } 100 \text { people tested will have the marker }\end{array}$ \\
\hline $\begin{array}{l}\text { Medical expert agreement on changing medical care based on } \\
\text { genetic marker }\end{array}$ & $\begin{array}{l}\text { - All experts agree } \\
\text { - Most experts agree } \\
\text { - Few experts agree }\end{array}$ \\
\hline $\begin{array}{l}\text { Change in your member's health and function if genetic } \\
\text { information leads to changed medical care plan }\end{array}$ & $\begin{array}{l}\text { - No change, poor } \\
\text { - Poor to fair } \\
\text { - Fair to excellent } \\
\text { - Poor to excellent }\end{array}$ \\
\hline $\begin{array}{l}\text { Likely change in your member's length of life expectancy if } \\
\text { genetic information leads to change in treatment }\end{array}$ & $\begin{array}{l}\text { - Between a gain of } 1 \text { month to a gain of } 5 \text { months, average gain of } 3 \text { months } \\
\text { - Between a loss of } 3 \text { months to a gain of } 9 \text { months, average gain of } 3 \text { months } \\
\text { - Between a gain of } 6 \text { months to a gain of } 1.5 \text { years, average gain of } 1 \text { year } \\
\text { - Between a loss of } 6 \text { months to a gain of } 2.5 \text { years, average gain of } 1 \text { year } \\
\text { - Between a gain of } 2 \text { years and a gain of } 6 \text { years, average gain of } 4 \text { years } \\
\text { - Between a gain of } 0 \text { years and a gain of } 8 \text { years, average gain of } 4 \text { years }\end{array}$ \\
\hline Cost of testing to your plan, USD & $\begin{array}{l}\cdot 25 \\
\cdot 100 \\
\cdot \\
\cdot\end{array}$ \\
\hline
\end{tabular}

USD =U.S. dollars.

estimate stakeholder preference about genomics. Specifically, DCEs have been used to evaluate patient preference for genetic counseling for cancer screening programs, cancer treatments, and the willingness to pay for different types of health care appointments among cancer patients. ${ }^{7,8}$ DCEs have also been used to evaluate provider preference, but there is a dearth of studies evaluating payer preference for genomic technologies despite their key role in determining access. ${ }^{3}$ The lack of data on payer preference for genetic precision medicine tests impedes test developer and researcher ability to develop and provide timely access to innovative tests.

The objective of our study was to elicit U.S. health care payer preference for covering precision medicine tests. We hypothesized that different characteristics of genetic tests would influence payer preference in reimbursement decision making. We chose to use DCEs for a preference-elicitation method to (a) rank the genetic tests attributes after estimating the relative importance of each attribute in reimbursement decision making and (b) determine payer marginal willingness-to-pay (mWTP) estimates for genetic testing attribute levels.

\section{Methods}

\section{Overview}

We first identified attributes and attribute levels that payers deemed important for their genetic testing reimbursement decision-making process. We then estimated the relative importance of the attributes in payer decision making by asking payers to choose between 2 hypothetical genetic tests with different test attributes in multiple choice tasks.

\section{Attributes and Levels Selection}

Choice of attributes and their levels is a critical aspect of DCE development. We identified the attributes and their levels using a combination of interviews and focus groups as described elsewhere. ${ }^{9}$ The identified attributes and their levels were confirmed for payers using payer interviews. We invited 17 payers for a qualitative interview in-person or over the phone to identify the attributes of a genetic test that are important in the reimbursement decision-making process. Of 17 payers invited, 6 payers provided consent and participated in the interviews and also completed a demographic questionnaire. The payers who consented were mostly from private for-profit plans (50\%), and a majority served as medical director (83.3\%). The qualitative interview, led by an experienced facilitator, was guided by available genetic test literature and expert opinion. Based on the qualitative interviews, we identified 6 attributes as important to payers for reimbursement of genetic tests: (a) type of information the test provides (screening vs. treatment prediction), (b) probability that the member has an informative genetic marker, (c) expert agreement on changing medical care based on the marker, (d) quality-of-life gains, (e) life expectancy gains (with statistical uncertainty), and (f) cost to the plan (Table 1). We defined disease screening tests as genetic tests that can identify people with an increased risk of developing a new disease. Treatment prediction tests were defined as 
TABLE 2 Example Choice Task Questions Offered to Respondents

Which of the following tests would you prefer?

\begin{tabular}{|c|c|c|c|}
\hline Test Characteristics & OptionA & Option B & \\
\hline Information from a genetic test & Disease screening & $\begin{array}{l}\text { Disease screening + treatment } \\
\text { change }\end{array}$ & \\
\hline Probability that your member has the genetic markers & $\begin{array}{l}1 \text { of } 100 \text { people tested will } \\
\text { have the marker }\end{array}$ & $\begin{array}{l}10 \text { of } 100 \text { people tested will } \\
\text { have the marker }\end{array}$ & \\
\hline $\begin{array}{l}\text { Medical expert agreement on changing medical care based on genetic } \\
\text { marker }\end{array}$ & Few experts agree & Most experts agree & \\
\hline $\begin{array}{l}\text { Change in your member's health and function if genetic information } \\
\text { leads to changed medical care plan }\end{array}$ & Poor to excellent & Fair to excellent & \\
\hline $\begin{array}{l}\text { Likely change in your member's length of life expectancy if genetic } \\
\text { information leads to change in treatment }\end{array}$ & $\begin{array}{l}\text { Between a loss of } 3 \text { months } \\
\text { to a gain of } 9 \text { months, average } \\
\text { gain of } 3 \text { months }\end{array}$ & $\begin{array}{l}\text { Between no gain and a gain } \\
\text { of } 8 \text { years, average gain of } 4 \\
\text { years }\end{array}$ & \\
\hline Cost of testing to your plan, USD & 500 & 3,000 & \\
\hline Which option would you prefer? (check one box) & Option A $\square$ & Option B $\square$ & Neither $\square$ \\
\hline
\end{tabular}

Note: This table offers an example of a choice question that was offered to respondents (payers). Each DCE respondent completed 16 choice tasks with scenarios that differed on 6 attributes. In each task, respondents were asked to choose between 2 alternate genetic tests with different characteristics. An opt-out or neither test alternative allowed for the possibility that the respondents did not want to choose either of the 2 genetic tests that were offered.

$D C E=$ discrete choice experiment $; U S D=U . S$. dollars.

genetic tests that can identify members who are likely to immediately benefit from a specific treatment for their current medical condition. Although genetic tests cannot improve patient quality of life or increase life expectancy directly, they can affect both through the clinical actions taken as a result of receiving information from the test (e.g., increased mammography screening or a change in a drug treatment plan).

We then identified the levels of each attribute of the genetic test that the U.S. health care payers are likely to come across in their genetic test reimbursement decision making (Table 1).

\section{Experimental Design}

We used the D-optimal approach with informative priors to design the choice-based experiment, which resulted in 144 choice tasks. D-optimal designs maximize the precision of the estimated parameters given a specific number of choice tasks and given the specified prior on the beta estimates. ${ }^{10}$ We assumed the cost to be continuous and all the other attribute levels to be categorical. The choice tasks were administered in 9 blocks, wherein each participant was randomized to 1 block consisting of 16 choice tasks. The participants were allowed to choose from either of the 2 choices presented or allowed to opt out. Participants were asked to choose from their preferred genetic test (Test A vs. Test B) for each choice task. An example choice task is presented in Table 2. The 2 genetic tests presented as choice sets were created by varying the levels of the 6 test attributes. The respondents were given an option to not choose any of the 2 presented alternatives.

\section{Instrument/Questionnaire Design}

The DCE survey included demographic and background information. We followed the Professional Society for Health
Economics and Outcomes Research good research practices for conjoint analysis applications in health care throughout our study. ${ }^{10-12}$ The survey also included a detailed description of the attributes and levels for the better understanding of the choice scenarios by the participants. We pretested the survey with a payer to assess the response burden, the time taken to complete the survey, and to ensure that participants could understand the survey and choice tasks. We finalized the survey design based on the pretesting responses and any concerns that the participants raised during the pretesting phase.

\section{Data Collection}

We hired a professional survey organization to administer the survey to 150 U.S. health care payers. The U.S. payers were initially contacted through email using an Internet sampling panel. The participants who consented were then referred to a password protected website to complete the survey. Of 258 payers targeted, 150 (58\%) payers completed the DCE. An introduction to the questionnaire and DCE was presented through a video education module that outlined the concept of PM and explained the choice task attributes (https://tinyurl. $\mathrm{com} / \mathrm{yd} 7 \mathrm{urm} 9 \mathrm{~b})$. After outlining the concept of genetic testing, the instructions described the 6 attributes of genetic tests included in this study in detail. The participants were asked to consider these attributes as some of the most important characteristics that are typically considered when reimbursing genetic tests. Each respondent was then randomly assigned to 1 of 9 blocks that included 16 choice tasks each. Before the choice tasks, the payers were asked to rank the 6 attributes in order of importance to them when deciding which test to reimburse.

Participants self-administered the survey through an online platform from September 2017 to October 2017. This study 


\begin{tabular}{|c|c|c|}
\hline & $\begin{array}{r}\text { Overa } \\
(\mathrm{N} \\
\mathrm{r}\end{array}$ & $\begin{array}{l}1 \text { Sample } \\
=150) \\
(\%)\end{array}$ \\
\hline \multicolumn{3}{|l|}{ Type of health system } \\
\hline Public & 43 & $(28.7)$ \\
\hline Private (nonprofit) & 70 & $(46.7)$ \\
\hline Private (for profit) & 37 & $(24.7)$ \\
\hline \multicolumn{3}{|l|}{ Role in health system } \\
\hline Medical director & 117 & (78) \\
\hline Pharmacy director & 18 & $(12)$ \\
\hline P\&T committee member & 15 & $(10)$ \\
\hline \multicolumn{3}{|l|}{ Education/training } \\
\hline Doctor of medicine & 116 & $(77.3)$ \\
\hline Doctor of osteopathic medicine & 7 & $(4.7)$ \\
\hline Doctor of pharmacy & 21 & $(14)$ \\
\hline Doctor of philosophy & 10 & $(6.7)$ \\
\hline Master of public health & 6 & (4) \\
\hline Other & 10 & $(6.7)$ \\
\hline \multicolumn{3}{|l|}{ Years in health care decision making } \\
\hline Less than 1 year & 1 & $(0.7)$ \\
\hline $1-4$ years & 21 & (14) \\
\hline 5 or more years & 128 & $(85)$ \\
\hline \multicolumn{3}{|l|}{ Evaluated a genetic test for coverage and reimbursement } \\
\hline Yes & 79 & $(52.7)$ \\
\hline No & 71 & $(47.3)$ \\
\hline \multicolumn{3}{|l|}{ Perception about technology } \\
\hline $\begin{array}{l}\text { I am skeptical of new technologies and use them only } \\
\text { when I have to }\end{array}$ & 2 & (1.4) \\
\hline $\begin{array}{l}\text { I am usually } 1 \text { of the last people I know to use new } \\
\text { technologies }\end{array}$ & 1 & $(0.7)$ \\
\hline I use new technologies when most people I know do & 43 & $(28.7)$ \\
\hline $\begin{array}{l}\text { I like new technologies and use them before most } \\
\text { people I know }\end{array}$ & 80 & $(53.3)$ \\
\hline $\begin{array}{l}\text { I love new technologies and am among the first to } \\
\text { experiment with and use them }\end{array}$ & 24 & (16) \\
\hline \multicolumn{3}{|l|}{$P E T=$ pharmacy and therapeutics. } \\
\hline
\end{tabular}

was approved by the Institutional Review Board at University of Washington, Seattle.

\section{Statistical Analyses}

All the analyses for this study were performed using STATA 13 software (StataCorp, College Station, TX). We used the error component mixed logit model to analyze the responses from the DCE. ${ }^{12}$ The error component accounts for the nested structure of the model (Test A/Test B vs. opt-out), addresses the within-participant correlation across choice tasks, and accounts for unobserved preference heterogeneity. ${ }^{13}$ The coefficient on opt-out indicator was constrained to zero and was assumed to be random and follow a normal distribution. This allows for correlation between the opt-in scenarios. The cost of the test to the plan and genetic marker probability were included as continuous variable and all other attributes were effect-coded and included as categorical covariates.
Cost parameter was modeled as a continuous variable to allow the estimation of the mWTP. The sign (positive or negative) of coefficients indicated whether the attribute level was preferred (not preferred) by the participant. A higher value of a coefficient represented a stronger preference of the attribute level and a lower positive value represented a weaker preference. A negative value of the coefficient of attribute level indicated the least desirable option. Effects coding is a restriction where the sum of utility contributions across all levels within a given attribute is zero. The estimated attribute levels are thus still relative to each other. ${ }^{14}$

\section{Results}

\section{Respondent Characteristics}

A total of 150 participants completed the survey (Table 3). Forty-three (29\%) of 150 participants were employed in the public sector, and 107 (71\%) were from the private sector. One hundred and seventeen (78\%) participants self-reported their role as medical director, 18 (12\%) reported their role as pharmacy director, and $15(10 \%)$ reported their role as pharmacy and therapeutics (P\&T) committee member.

Most participants $(\approx 77 \%)$ self-reported their training and education as MD, and 21 (14\%) participants reported holding a PharmD degree. Most of the payers ( $\approx 85 \%)$ who participated had more than 5 years of experience in health care decision making. Approximately half $(\approx 53 \%)$ of participants had prior experience evaluating a genetic test for coverage and reimbursement (Table 3).

\section{Attribute-Level Preferences}

Part-worth utility values, which measure how much the respondent's decision to make a specific choice was influenced by each attribute and attribute levels, for the attributes and levels are presented in Figure 1 (see also Appendix A, available in online article). The coefficient of cost was negative, and it shows that an increase in the cost to plan for genetic test decreased payer utility for reimbursement of the genetic tests. The coefficients for the probability that a plan member has the genetic marker of interest was positive, that is, payer preference of reimbursing genetic testing increased with an increase in the probability of genetic marker among the members of the plan.

All else equal, the payers had disutility if the genetic test was used for screening alone compared with the use of the genetic test for treatment alone or screening plus treatment combined. In other words, payers preferred tests that guided treatment decision rather than preventative actions. Payers had disutility for genetic tests that resulted in lower medical expert agreement for change in medical care compared with tests resulting in higher medical expert agreement. The payers had a higher preference for genetic tests that resulted in greater changes in quantity and quality of life. Payers also preferred genetic tests that had lower uncertainty around the quantity 


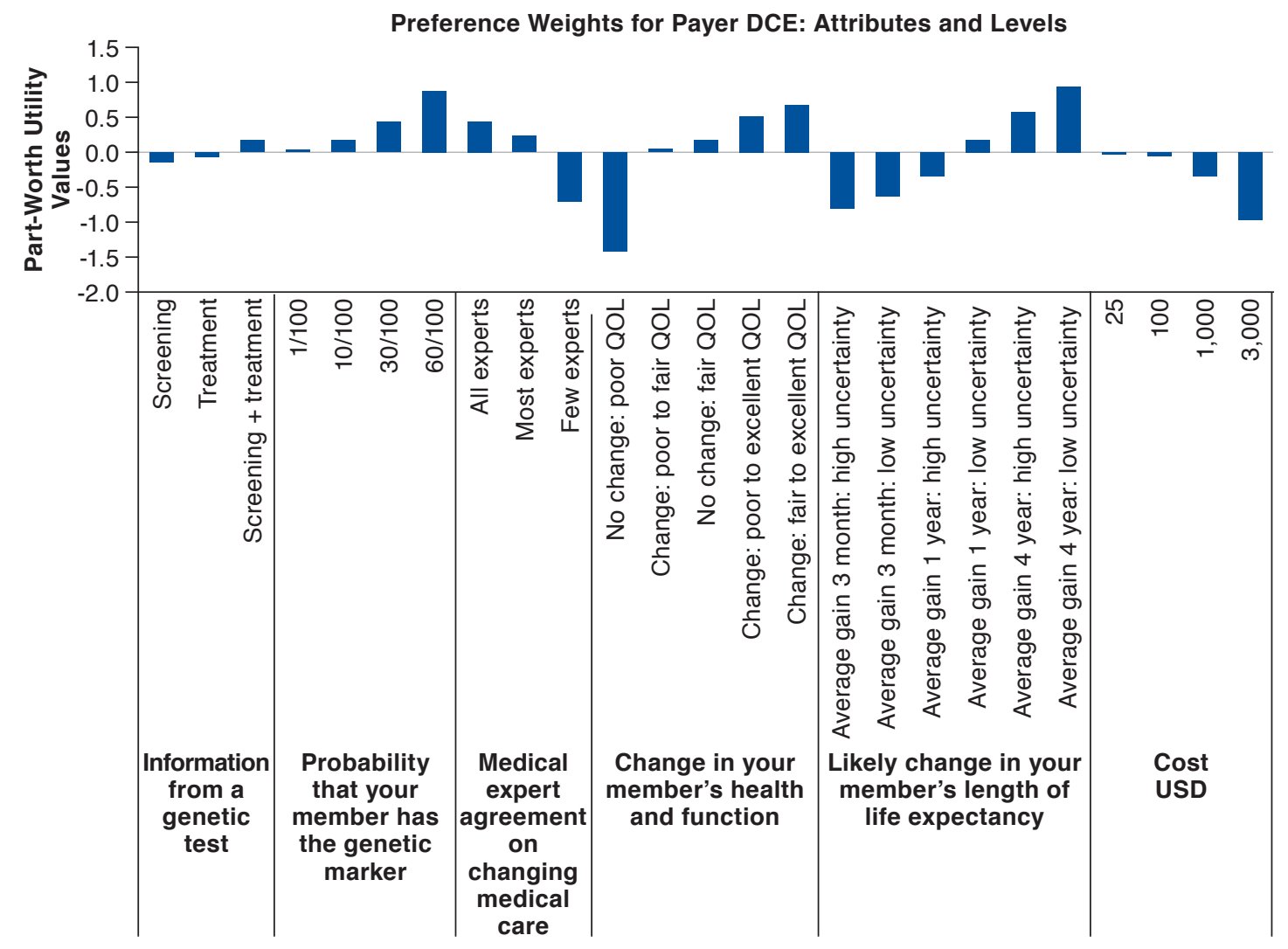

Note: This figure contains estimated part-worth utilities from the discrete choice experiment. The estimates presented here are based on the error component mixed logit model. $D C E=$ discrete choice experiment; $2 O L=$ quality of life; USD =U.S. dollars.

of life, for example, among 2 tests that resulted in a quantity of life improvements of 3 months, the payers preferred lower uncertainty about life expectancy gains compared with higher uncertainty. Payers preferred the tests with lower plan costs compared with the tests with higher plan costs.

\section{Relative Importance of Attributes}

The relative importance of attributes over the range of levels included in this DCE is shown in Appendix B (available in online article). Based on payer preference, the most important attribute of a genetic test was quality-of-life changes, that is, change in plan member health and function. Change in plan member length of life expectancy was the second most important attribute. Medical expert agreement, the probability that the member has the genetic marker, and cost of the genetic test to the plan had similar relative importance. The information provided by genetic tests, that is, whether the test is used for screening only, treatment only, or both, had the least relative importance among all the attributes.

\section{Marginal Willingness-to-Pay Estimates}

We estimated payer mWTP by comparing the differences in the levels of attributes to the cost coefficient (Figure 2). Payer mWTP estimates were highest $(\$ 6,076,95 \%$ confidence interval $[C I]=\$ 4,955-\$ 7,857$ ) for quality-of-life improvements in the plan members-when the member's health was stated to change from poor to excellent based on the results of the genetic testing. Payers mWTP estimates were \$4,962 (95\% $\mathrm{CI}=\$ 4,046-\$ 6,415)$ for a change in the quality of life from poor to fair. The mWTP for a quality-of-life change of the member from fair to excellent was $\$ 2,031$ (95\% CI $=\$ 1,656-\$ 2,627$ ).

Payer mWTP for a test that had all medical experts agreeing compared with a test that had few experts agreeing for a change in the medical treatment of the plan member was $\$ 3,489$ (95\% $\mathrm{CI}=\$ 2,845-\$ 4,511$; Figure 2). The mWTP for a test that had few experts agreeing compared with the test that had most experts agreeing for a change in the medical treatment for the plan member was $\$ 2,881$, and the mWTP for a test that had most experts 
Payer Preferences and Willingness to Pay for Genomic Precision Medicine: A Discrete Choice Experiment

FIGURE 2 Tornado Plot of Marginal Willingness to Pay for Change in Attribute Levels

mWTP (USD) for Change in Attribute Levels: Based on the U.S. Payer's Preference

QOL: no change poor to change of poor excellent

QOL: no change poor to change of poor to fair

Expert agreement: change from few to all experts

Expert agreement: change from few to most experts

Marker probability: change from $1 \%$ to $60 \%$

Marker probability: change from $10 \%$ to $60 \%$

QOL: no change fair to change of fair to excellent

Life expectancy (1 year): change of high to low uncertainty

QOL: change of poor to fair to change of poor to excellent

Marker probability: change from $30 \%$ to $60 \%$

Marker probability: change from $1 \%$ to $30 \%$

Life expectancy (4 years): change of high to low uncertainty

Marker probability: change from $10 \%$ to $30 \%$

Expert agreement: change from most experts to all experts

Life expectancy (3 months): change of high to low uncertainty

Marker probability: change from $1 \%$ to $10 \%$

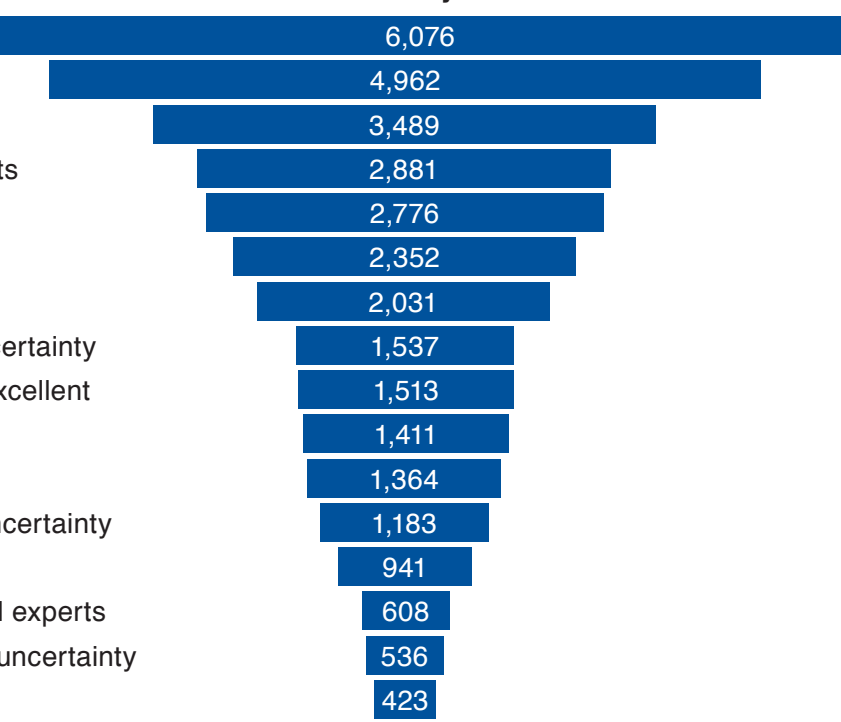

mWTP, USD (95\% Cl)

$(4,955-7,857)$

$(4,046-6,415)$

$2,845-4,511)$

(2,349-3,725)

(2,264-3,589)

$(1,918-3,042)$

$(1,656-2,627)$

(1,253-1,987)

(1,234-1,957)

$(1,151-1,825)$

(1,113-1,764)

(965-1,530)

$(767-1,217)$

(496- 786)

(437-693)

(345-547)

Note: The estimates were based on the error component mixed logit regression model. We dummy coded the categoric attributes and cost and probability that the member has the genetic marker were continuous variables. Each main-effect attribute level was included in the model. We specified constraints that normalized the parameter of the reference level to zero for identification purposes.

$C I=$ confidence interval; $m W T P=$ marginal willingness to pay; $Q O L=$ quality of life; USD $=U . S$. dollars.

agreeing compared with all experts agreeing for a change in the medical treatment was $\$ 608$ (95\% CI $=\$ 496-\$ 786)$.

The probability that a plan member had the genetic marker of interest was important for the payers (Figure 2). The mWTP for a test for a genetic marker that had $1 \%$ prevalence compared with a test for a genetic marker that had a prevalence of $60 \%$ was $\$ 2,776$ (95\% CI $=\$ 2,264-\$ 3,589$ ), whereas the mWTP for a test with marker probability of $1 \%$ compared with a test with marker probability of $10 \%$ was $\$ 423$ (95\% CI $=\$ 345-\$ 547)$.

Payers stated higher utility for reduced statistical uncertainty around improvements in life expectancy (survival gains). Payer mWTP for a reduction in statistical uncertainty from high to low for a 1-year survival gain was $\$ 1,537$ (95\% $C I=\$ 1,253-\$ 1,987$ ), for a reduction in uncertainty for a 4-year survival gain was $\$ 1,183$ (95\% CI $=\$ 965-\$ 1,530)$, and a reduction in uncertainty for a 3-month survival gain was \$536 (95\% $\mathrm{CI}=\$ 437-\$ 693)$.

\section{Discussion}

We elicited the U.S. payer preference for attributes and levels representing the characteristics for genetic tests used for disease risk screening and treatment of diseases. We used a sequential mixed methods approach to identify the attributes and a DCE survey to elicit payer preference. We found that payers assigned the most importance to the life expectancy and quality-of-life gains of plan members. We also found that uncertainty and expert agreement were important attributes.

This was the first study to elicit and quantify the preferences of U.S. payers for genetic testing used for disease risk screening and/or treatment decisions. The results of our study have several implications. Our findings indicate that payers value increased certainty and may be willing to trade off certainty for higher attribute levels in other areas. These findings could be used to enhance health technology assessment activities highlighting key areas for evidence gathering, generation, and presentation aligned with payer preference. This may, in turn, facilitate timely and fully informed coverage and reimbursement decisions. For example, the information and evidence about new genetic tests could be incorporated into existing guidance of coverage and reimbursement of genetic tests, for example, Palmetto GBA, and the AMCP Format for Formulary Submissions.

The results of this study can be used along with patient and provider preferences to make predictions about genetic test diffusion. Predictions about test diffusion can be useful for test developers with regard to market planning, pricing, and evidence generation. It can further be used by payers to inform financial planning and future budget impact estimates. Finally, these data can be used to estimate the value of conducting additional research about a genetic test and inform 
coverage and reimbursement decisions to accept, deny, or seek additional data.

In an interesting finding from our study, the payers stated higher utility (mWTP of $\$ 3,489 ; 95 \% \mathrm{CI}=\$ 2,845-\$ 4,511$ ) for a genetic test that had all medical experts agreeing compared with a test that had few experts agreeing for a change in the medical treatment of the plan member, but the stated utility for a genetic test that reduces statistical uncertainty in life expectancy (survival gains) was relatively low (e.g., mWTP for a reduction in uncertainty for a 4-year survival gain was $\$ 1,183$, 95\% CI $=\$ 965$ $\$ 1,530$; Figure 2). Although both of these attributes deal with aspects of uncertainty, this finding may indicate that payers have a stronger preference for clinical consensus versus statistical precision. It is also noteworthy that respondent preference for the cost attribute ranked relatively low at fifth of 6 attributes (Appendix B) indicating the payers may be somewhat price insensitive when it comes to genetic tests.

There is limited evidence for provider preference for genetic tests used for screening purposes versus informing treatment decisions, although several studies have evaluated patient preference in this area. Weymann et al. (2018) elicited patient preference for next-generation sequencing for colorectal cancer risk..$^{15}$ The authors found that patients preferred genetic tests with higher genetic marker probability and smaller wait times. In another study, Najafzadeh et al. (2013) elicited preferences of general public and cancer patients for genetic test for guiding cancer treatment and found that patients and the general public preferred genetic tests with higher sensitivity (95\% vs. $50 \%) .{ }^{16}$ The authors also estimated a willingness to pay of $\$ 1,331$ for improvement in test sensitivity from 50\% to 95\% for an aggressively curable cancer. Buchannan et al. (2016) elicited patient preference for genomic screening in chronic lymphocytic leukemia in the United Kingdom. ${ }^{17}$

The researchers found that patients prefer tests that are more effective, more reliable, cheaper, and quickly return results. Regier et al. (2009) evaluated preference of patients' families for the use of genetic testing in developmental disability and found that families prefer tests with higher diagnostic yield and shorter wait times. ${ }^{18}$ In summary, these studies suggest patients and payers have overlapping preferences, but payers are also interested in expert consensus and greater certainty in estimates of clinical benefit.

\section{Limitations}

Our study has several limitations. First, because of the generalized nature of the hypothetical genetic tests from which we asked the payers to choose, the results of our study may not be directly applicable to specific genetic tests used for screening or treatment.

Second, the attributes selection process included qualitative data from patients and providers. Therefore, some attributes that may have been solely important for the payers may have not been selected.

Third, we used a probabilistic sample of the payer population to recruit the respondents using an online professional survey organization and an online panel. This group may not be fully generalizable to the entire U.S. payer population, and there may be some bias due to unobservable payer characteristics.

Fourth, additional attributes may also be important to payers, but the DCE survey methodology must balance the number of attributes included against the patient burden and cognitive complexity of the tasks.

Fifth, we pretested our DCE survey on 1 payer only. The potential implication of having a small sample for pretesting is that the range of some attribute levels included may not capture the preferences of the respondents. However, we did not observe such phenomenon, and we observed that the attribute levels were sensitive to respondent preference.

Sixth, we did not include the analysis of preference heterogeneity among payers based on their geographic location or size. Finally, the response rate of DCE survey was 58\%, and we did not collect data for those who participated versus those who did not participate.

\section{Conclusions}

We evaluated payer preference for precision medicine. We found that payer demand for precision medicine is driven by clinical benefits-improvements in life expectancy and quality of life, and, of importance, increases with reduction in uncertainty around these benefits and with higher expert agreement on recommended medical actions. Our findings suggest that payers will demand evidence of clinical utility in terms of patient comprehensive health outcomes as well as clinical consensus about appropriate use to support coverage and reimbursement policies favorable to precision medicine testing. Future work will be required to better understand evidence thresholds for specific types of precision medicine tests.

\section{Authors}

DEVENDER S. DHANDA, PhD, MS, MBA; DAVID L. VEENSTRA, PharmD, PhD; ANIRBAN BASU, PhD; and JOSH J. CARLSON, $\mathrm{MPH}, \mathrm{PhD}$, The Comparative Health Outcomes, Policy \& Economics (CHOICE) Institute, University of Washington School of Pharmacy, Seattle. DEAN A. REGIER, PhD, School of Population and Public Health, University of British Columbia, and Canadian Centre for Applied Research in Cancer Control (ARCC), BC Cancer, Vancouver, $B C$, Canada.

AUTHOR CORRESPONDENCE: Josh J. Carlson, MPH, PhD, The CHOICE Institute, University of Washington Department of Pharmacy, Box 357630, Seattle, WA 98195-7630.

Tel.: 206.543.9649; E-mail: Carlsojj@u.washington.edu. 


\section{DISCLOSURES}

This study was supported by a grant from the NIH Common Fund and NIA (IU01AG047109-01) via the Personalized Medicine Economics Research (PriMER) project. Unrelated to this study, Veenstra reports consulting fees from Bayer and Halozyme; Basu reports consulting fees from Salutis Consulting; and Reiger reports consulting fees from Roche. Carlson reports grants from Institute for Clinical and Economic Review, during the conduct of this study, and consulting fees from Bayer, Adaptive Biotechnologies, Allergan, Galderma, and Vifor Pharma, unrelated to this study.

\section{REFERENCES}

1. Ginsburg GS, Phillips KA. Precision medicine: from science to value. Health Aff (Millwood). 2018;37(5):694-701.

2. Phillips KA, Trosman JR, Kelley RK, Pletcher MJ, Douglas MP, Weldon CB. Genomic sequencing: assessing the health care system, policy, and big-data implications. Health Aff (Millwood). 2014;33(7):1246-53.

3. Messner DA, Al Naber J, Koay P, et al. Barriers to clinical adoption of next generation sequencing: perspectives of a policy Delphi panel. Appl Transl Genom. 2016;10:19-24.

4. Lu CY, Loomer S, Ceccarelli R, et al. Insurance coverage policies for pharmacogenomic and multi-gene testing for cancer. J Pers Med. 2018;8(2) pii: E19.

5. Dervan AP, Deverka PA, Trosman JR, Weldon CB, Douglas MP, Phillips KA. Payer decision making for next-generation sequencing-based genetic tests: insights from cell-free DNA prenatal screening. Genet Med. 2017;19(5):559-67.

6. Phillips KA, Trosman JR, Deverka PA, et al. Insurance coverage for genomic tests. Science. 2018;360(6386):278-79.

7. Regier DA, Weymann D, Buchanan J, Marshall DA, Wordsworth S. Valuation of health and nonhealth outcomes from next-generation sequencing: approaches, challenges, and solutions. Value Health. 2018;21(9):1043-47.

8. Wong SF, Norman R, Dunning TL, et al. A discrete choice experiment to examine the preferences of patients with cancer and their willingness to pay for different types of health care appointments. J Natl Compr Canc Netw. 2016;14(3):311-19.
9. Regier DA, Veenstra DL, Basu A, Carlson JJ. Demand for precision medicine: a discrete-choice experiment and external validation study. Pharmacoeconomics. 2019;38(1):57-68.

10. Reed Johnson F, Lancsar E, Marshall D, et al. Constructing experimental designs for discrete-choice experiments: report of the ISPOR Conjoint Analysis Experimental Design Good Research Practices Task Force. Value Health. 2013;16(1):3-13.

11. Bridges JF, Hauber AB, Marshall D, et al. Conjoint analysis applications in health-a checklist: a report of the ISPOR Good Research Practices for Conjoint Analysis Task Force. Value Health. 2011;14(4):403-13.

12. Hole A. Fitting mixed logit models by using maximum simulated likelihood. Stata J. 2007;7(3):388-401.

13. Hauber AB, Gonzalez JM, Groothuis-Oudshoorn CG, et al. Statistical methods for the analysis of discrete choice experiments: a report of the ISPOR Conjoint Analysis Good Research Practices Task Force. Value Health. 2016;19(4):300-15.

14. Daly A, Dekker T, Hess S. Dummy coding vs effects coding for categorical variables: clarifications and extensions. J Choice Modelling. 2016;21(C):36-41.

15. Weymann D, Veenstra DL, Jarvik GP, Regier DA. Patient preferences for massively parallel sequencing genetic testing of colorectal cancer risk: a discrete choice experiment. Eur J Hum Genet. 2018;26(9):1257-65.

16. Najafzadeh M, Johnston KM, Peacock SJ, et al. Genomic testing to determine drug response: measuring preferences of the public and patients using Discrete Choice Experiment (DCE). BMC Health Serv Res. 2013;13:454.

17. Buchanan J, Wordsworth S, Schuh A. Patients' preferences for genomic diagnostic testing in chronic lymphocytic leukaemia: a discrete choice experiment. Patient. 2016;9(6):525-36

18. Regier DA, Friedman JM, Makela N, Ryan M, Marra CA. Valuing the benefit of diagnostic testing for genetic causes of idiopathic developmental disability: willingness to pay from families of affected children. Clin Genet. 2009;75(6):514-21. 


\begin{tabular}{|c|c|c|c|}
\hline APPENDIX & $\begin{array}{l}\text { Results of the Er } \\
\text { Mixed Logit Mo } \\
\text { the Discrete Cho } \\
\text { Payers }\end{array}$ & $\begin{array}{l}\text { or Compo } \\
\text { el for the } \\
\text { ce Experir }\end{array}$ & $\begin{array}{l}\text { hents } \\
\text { Results of } \\
\text { hent for }\end{array}$ \\
\hline Attribute & Level & $\begin{array}{c}\text { Part-Worth } \\
\text { Utility }\end{array}$ & $\begin{array}{l}\text { Standard } \\
\text { Error }\end{array}$ \\
\hline Intended test use & Screening & -0.1074 & 0.0587 \\
\hline & Treatment & -0.0498 & 0.0530 \\
\hline & Screening and treatment & $0.1572^{\mathrm{a}}$ & 0.0623 \\
\hline $\begin{array}{l}\text { Probability of } \\
\text { member having the } \\
\text { genetic marker }\end{array}$ & $\begin{array}{l}\text { Per } 0.1 \text { increase in } \\
\text { probability (up to } 0.6 \text { ) }\end{array}$ & $1.489^{a}$ & 0.2004 \\
\hline Expert agreement & All experts & $0.4321^{\mathrm{a}}$ & 0.0674 \\
\hline on using the test to & Most experts & $0.2397^{\mathrm{a}}$ & 0.0505 \\
\hline & Few experts & $-0.6718^{a}$ & 0.0792 \\
\hline Change in plan & No change: poor & $-1.404^{b}$ & 0.4107 \\
\hline member health and & From poor to fair & 0.0392 & 0.1021 \\
\hline & No change: fair & 0.1653 & 0.1656 \\
\hline & From poor to excellent & $0.5180^{\mathrm{a}}$ & 0.1091 \\
\hline & From fair to excellent & $0.6820^{a}$ & 0.1309 \\
\hline $\begin{array}{l}\text { Change in plan } \\
\text { member life }\end{array}$ & $\begin{array}{l}\text { Average gain } 3 \text { months: } \\
\pm 6 \text { months }\end{array}$ & $-0.7781^{\mathrm{a}}$ & 0.101737 \\
\hline expectancy & $\begin{array}{l}\text { Average gain of } 3 \\
\text { months: } \pm 2 \text { months }\end{array}$ & $-0.6085^{a}$ & 0.1006 \\
\hline & $\begin{array}{l}\text { Average gain of } 1 \text { year: } \\
\pm 18 \text { months }\end{array}$ & $-0.3134 b$ & 0.0887 \\
\hline & $\begin{array}{l}\text { Average gain of } 1 \text { year: } \\
\pm 6 \text { months }\end{array}$ & 0.1729 & 0.0852 \\
\hline & $\begin{array}{l}\text { Average gain of } 4 \text { years: } \\
\pm 4 \text { years }\end{array}$ & $0.5764^{a}$ & 0.1041 \\
\hline & $\begin{array}{l}\text { Average gain of } 4 \text { years: } \\
\pm 2 \text { years }\end{array}$ & $0.9507^{\mathrm{a}}$ & 0.0931 \\
\hline Cost of test & Per \$ increase & $-0.000316^{a}$ & 0.00004 \\
\hline $\begin{array}{l}\text { Note: The sample consi } \\
\text { Robust standard errors } \\
{ }^{a} P<0.005 \text { relative to tl } \\
{ }^{b} P<0.05 \text { relative to the }\end{array}$ & $\begin{array}{l}\text { ts of } 16 \text { completed choice tas } \\
\text { are clustered on the individu } \\
\text { e utility of opting out (i.e., z } \\
\text { utility of opting out (i.e., zer }\end{array}$ & $\begin{array}{l}\text { from each of } 15 \\
\text { respondent. } \\
\text { part-worth ut } \\
\text { part-worth util }\end{array}$ & $\begin{array}{l}\text { participants } \\
\text { ity). }\end{array}$ \\
\hline
\end{tabular}

\begin{tabular}{|c|c|c|c|}
\hline \multicolumn{4}{|c|}{$\begin{array}{l}\text { APPENDIX B Mean Ranking of the Attributes for } \\
\text { Genetic Tests }{ }^{\mathrm{a}}\end{array}$} \\
\hline Attributes & $\begin{array}{l}\text { Mean } \\
\text { Ranking }\end{array}$ & $\begin{array}{c}\text { Ranking } \\
\text { (Stated by } \\
\text { Payers Before } \\
\text { DCE) }\end{array}$ & $\begin{array}{c}\text { Ranking } \\
\text { (Based on } \\
\text { Payer DCE } \\
\text { Preferences) }\end{array}$ \\
\hline Information from a genetic test & 2.66 & \begin{tabular}{|l|}
1 \\
\end{tabular} & 6 \\
\hline $\begin{array}{l}\text { Probability that plan members } \\
\text { have the genetic marker }\end{array}$ & 3.89 & 5 & 3 \\
\hline $\begin{array}{l}\text { Medical expert agreement on } \\
\text { changing medical care }\end{array}$ & 3.77 & 4 & 4 \\
\hline $\begin{array}{l}\text { Change in plan member health } \\
\text { and function }\end{array}$ & 2.99 & 2 & 1 \\
\hline $\begin{array}{l}\text { Likely change in plan member } \\
\text { length of life expectancy }\end{array}$ & 3.40 & 3 & 2 \\
\hline Cost of genetic test & 4.28 & 6 & 5 \\
\hline \multicolumn{4}{|c|}{$\begin{array}{l}\text { aBased on the stated rankings (before the discrete choice task) task compared with } \\
\text { the ranking based on the DCE. } \\
D C E=\text { discrete choice experiment. }\end{array}$} \\
\hline
\end{tabular}

